\title{
RIGHT VENTRICULAR EJECTION FRACTION IN THE PREOPERATIVE RISK EVALUATION OF CANDIDATES FOR PULMONARY RESECTION
}

\author{
Morihito Okada, MD \\ Masayoshi Okada, MD \\ Noboru Ishii, MD \\ Chojiro Yamashita, MD \\ Takaki Sugimoto, MD \\ Kenji Okada, MD \\ Hiroyuki Yamagishi, MD \\ Teruo Yamashita, MD \\ Hitoshi Matsuda, MD
}

The major determinants of postoperative morbidity and mortality after lung resection are the physiologic and functional statuses of the pulmonary and cardiac systems. In our previous study, serial measurements of right ventricular performance after pulmonary resection demonstrated significant right ventricular dysfunction in the postoperative period. This study evaluates the preoperative measurement of right ventricular ejection fraction as a predictor of postoperative complications. In addition to conventional cardiopulmonary functional tests, right ventricular function was assessed with a thermodilution technique at rest and during exercise in 18 patients before and 3 weeks after lobectomy or pneumonectomy. The patients were grouped according to severity of right ventricular functional defect: right ventricular ejection fraction of at least $45 \%$ (group Ia, $n=8$ ), right ventricular ejection fraction less than $45 \%$ (group $\mathrm{Ib}, n=10$ ), exercise-induced increases in right ventricular ejection fraction (group IIa, $n=8$ ), and exercise-induced decreases in right ventricular ejection fraction (group IIb, $n=10$ ). Postoperative cardiopulmonary morbidity was recorded for two patients $(25 \%)$ in group Ia, three patients $(30 \%)$ in group Ib, no patients $(0 \%)$ in group IIa, and five patients $(50 \%)$ in group IIb. Postoperative hospital stay was $28.9 \pm 8.5$ days in group Ia, $29.9 \pm 20.2$ days in group Ib, $19.4 \pm 8.0$ days in group IIa, and $37.5 \pm 15.9$ days in group IIb ( $p<0.05$, group IIa vs group IIb). Although resection-induced changes in forced expiratory volume in 1 second did not differ significantly between group Ia and group Ib, these values appeared to be increased in groups IIa (not statistically significant) and IIb (significantly, $p<0.05$ ). The measured postoperative values of forced expiratory volume in 1 second and vital capacity were significantly higher than the predicted postoperative values $(p<0.05$ ) in group IIa, but not in groups Ia, Ib, and IIb. We conclude that evaluation of right ventricular performance is useful in determining which patients are at increased risk for medical complications after lung resection. Exercise-induced change in right ventricular ejection fraction may be a better indicator of high risk among candidates for pulmonary resection than the absolute value of this parameter. ( $J$ Thorac Cardiovasc Surg 1996;112:364-70)
$\mathrm{B}$ ecause of common etiologic factors, cardiopulmonary dysfunction often coexists with primary lung cancer, for which surgical resection remains the option with the most potential for cure in patients with localized disease without metastases. The major determinant of postoperative morbidity and

From the Department of Surgery, Division II, Kobe University School of Medicine, Kobe, Japan.

Received for publication July 26, 1995; revisions requested Sept. 15, 1995; revisions received Dec. 28, 1995; accepted for publication Jan. 3, 1996. mortality after pulmonary resection is the functional status of the cardiac and pulmonary systems. Clinicians are frequently faced with the problem of considering pulmonary resection for lung cancer in a patient with cardiopulmonary impairment. The functional loss resulting from pulmonary resection

\footnotetext{
Address for reprints: Morihito Okada, MD, Department of Surgery, Division II, Kobe University School of Medicine, Kusunoki-cho 7-5-2, Chuo-ku, Kobe, 650 Japan.

Copyright 101996 by Mosby-Year Book, Inc.

$0022-5223 / 96 \$ 5.00+0 \quad \mathbf{1 2 / 1 / 7 1 5 9 9}$
} 
varies with the extent of resection, the relative function of the tissue removed compared with that remaining, and the degree of baseline disease. It has been difficult to define the lower limit at which the operative morbidity and mortality exceeds the benefit of operative intervention. Indexes of pulmonary ventilatory function and gas exchange have been shown to be predictive of survival and complications after pulmonary resection. ${ }^{1-5}$ The predictive value of preoperative exercise performance parameters, such as maximum oxygen consumption and decrease in oxygen saturation with exercise, has remained controversial. ${ }^{1,6-8}$

We previously demonstrated that serial measurements of right ventricular performance after major pulmonary resection demonstrated significant right ventricular dilatation and dysfunction in the postoperative period. ${ }^{9}$ Although right ventricular performance has been shown to be important in varying medical conditions because it is subject to the effects of lung situations, ${ }^{10,11}$ surprisingly little information exists concerning the function of the right side of the heart as a predictor of complications after pulmonary resection. This study evaluated right ventricular ejection fraction (RVEF) at rest and after exercise before major pulmonary resection to determine the utility of this parameter in predicting postoperative complications.

\section{Patients and methods}

Patient population. The study population consisted of 18 consecutive patients with primary lung cancer who underwent either pneumonectomy or lobectomy and were able to satisfactorily complete cardiopulmonary function tests both before and after operation. Patients who underwent right pneumonectomy were excluded from examination because of the structure of the RVEF catheter used. The tip of the catheter should not be placed in the left side of the pulmonary artery. It is essential that the catheter with the thermistor be at a minimal distance from the pulmonary valve and that the injection port be within the right atrium to obtain an optimal RVEF value. The average patient age was $62 \pm 7$ years (range, 53 to 77 years). There were 17 men and one woman. No patient had a previous clinical history of coronary artery disease, valvular heart disease, hypertension, or arrhythmias. In addition, none of the patients had a significant adverse medical history or were taking any cardiopulmonary medications. Results of physical examination and electrocardiography at rest were unremarkable. None of the patients had clinically detectable tricuspid regurgitation, which could create significant errors in thermodilution RVEF measurements. ${ }^{12}$ Surgical procedures included five right lower lobectomies, three right upper lobectomies, three left lower lobectomies, three left pneumonectomies, three left upper lobectomies, and one right middle and lower lobectomy with dissection of the mediastinal lymph nodes. After this protocol was approved by the institutional review board, informed consent to participate in this study was obtained from all patients.

Protocol. All patients were placed in the supine position for at least 10 minutes before examination. Singlestage, submaximal exercise at fixed workloads was performed with a supine bicycle ergometer. This approach provided steady-state, aerobic exercise conditions. The workload was 80 watts for 5 minutes. During exercise, the patients lifted their feet, with the pedal axis located $30 \mathrm{~cm}$ higher than the table level, and began pedaling at a constant rate of $65 \mathrm{rpm}$. Measurements were obtained during the last 2 minutes of each 5-minute period.

Measurements. A multilumen $7.5 \mathrm{~F}$ catheter mounted with a rapid-response thermistor (Baxter Healthcare Corp, Irvine, Calif.) was inserted through the internal jugular vein into the pulmonary artery $3 \mathrm{~cm}$ distal to the pulmonary valve. The catheter position was confirmed radiographically and by examination of the characteristic pressure curve. Signals from this catheter were processed through a thermodilution ejection fraction computer (REF-1; Baxter). Cardiac output (CO) was determined, and the RVEF was computed by the thermodilution method as previously described elsewhere. ${ }^{13,14}$ A $5 \mathrm{ml}$ bolus of iced $5 \%$ dextrose in water was injected into the right atrium over 1.5 seconds. The subsequent temperature changes within the pulmonary artery were measured and then approximated as an exponential decay process. The rate of temperature decay between two successive right ventricular contractions was calculated. The rate of temperature change was then transformed to RVEF and expressed as a percentage. Other parameters measured included pulmonary artery pressure (PAP) and $\mathrm{CO}$. Heart rate (HR) was measured by electrocardiography. Systemic arterial pressure (BP) was obtained from direct brachial artery cannulation. Measurements were performed before induction of anesthesia and on the third postoperative week.

All patients underwent spirometry concurrently with the hemodynamic studies performed before and after the operation. Spirometric tracings were obtained by means of a standard pulmonary function testing system (Autospirometer System 9; Minato Medical Science Co., Ltd., Osaka, Japan) with patients in a seated upright position. The most consistent value of three tracings was used for analysis. Static lung volumes were measured with a constant-volume, whole-body plethysmograph ${ }^{15}$ and compared with the normal values reported by Goldman and Becklake. ${ }^{16}$ The vital capacity (VC), forced vital capacity (FVC), and forced expiratory volume in 1 second $\left(\mathrm{FEV}_{1.0}\right)$ were determined. The percentage of VC $(\% \mathrm{VC})$ referred to the relationship of the value obtained to the normal value corrected for the patient's sex, age, and height. The percentage of FVC expired in 1 second, that is, $\mathrm{FEV}_{1.0} / \mathrm{FVC}\left(\mathrm{FEV}_{1.0 \%}\right)$ was calculated. The expected lung function loss was calculated as the preoperative number of functional segments in the lobe to be resected divided by the total number of segments in both lungs. ${ }^{3,17}$ The number of functional segments was derived from ventilation-perfusion scans. The complete absence of radioactivity in a specific lung lobe was interpreted as total 
Table I. Clinical correlates of postoperative complications and periods

\begin{tabular}{|c|c|c|c|c|c|}
\hline \multirow[b]{2}{*}{ Parameter } & \multirow{2}{*}{$\begin{array}{c}\text { No. of } \\
\text { patients }\end{array}$} & \multicolumn{2}{|c|}{ Complication } & \multicolumn{2}{|c|}{ Length of stay } \\
\hline & & No. & $\%$ & Days & $p$ \\
\hline \multicolumn{6}{|l|}{ Predicted $\mathrm{FEV}_{1.0}(\mathrm{~L})$} \\
\hline$\geq 1.8$ & 10 & 1 & 10 & $24.6 \pm 12.1$ & \multirow[b]{2}{*}{ NS } \\
\hline$<1.8$ & 8 & 4 & 50 & $35.5 \pm 18.2$ & \\
\hline \multicolumn{6}{|c|}{ Preoperative $\mathrm{FEV}_{1.0} \%$} \\
\hline$\geq 75 \%$ & 12 & 2 & 17 & $29.3 \pm 17.9$ & \multirow{2}{*}{ NS } \\
\hline$<75 \%$ & 6 & 3 & 50 & $29.8 \pm 11.4$ & \\
\hline \multicolumn{6}{|l|}{ Predicted VC (L) } \\
\hline$\geq 2.0$ & 12 & 1 & 8 & $26.6 \pm 11.9$ & \multirow{2}{*}{ NS } \\
\hline$<2.0$ & 6 & 4 & 67 & $35.2 \pm 21.6$ & \\
\hline \multicolumn{6}{|l|}{ Predicted $\% \mathrm{VC}$} \\
\hline$\geq 65 \%$ & 11 & 1 & 9 & $25.5 \pm 11.9$ & \multirow{2}{*}{ NS } \\
\hline$<65 \%$ & 7 & 4 & 57 & $35.6 \pm 19.7$ & \\
\hline \multicolumn{6}{|c|}{ Preoperative RVEF (\%) } \\
\hline$\geq 45$ & 8 & 2 & 25 & $28.9 \pm 8.5$ & \multirow{2}{*}{ NS } \\
\hline$<45$ & 10 & 3 & 30 & $29.9 \pm 20.2$ & \\
\hline \multicolumn{6}{|c|}{ Effects of exercise on RVEF } \\
\hline Increase & 8 & 0 & 0 & $19.4 \pm 8.0$ & \multirow{2}{*}{$<0.05$} \\
\hline Decrease & 10 & 5 & 50 & $37.5 \pm 15.9$ & \\
\hline
\end{tabular}

All values are mean \pm standard deviation. $F E V_{1.0} \%, \mathrm{FEV}_{1.0} / \mathrm{FVC} ; N S$, not significant

dysfunction of that particular area, indicating that the predicted postoperative value should be considered equivalent to the postoperative measured value. When the lobar function was presumed to be adequate, however, the predicted postoperative value was calculated by subtracting the amount of anticipated functional loss from surgical resection of the diseased lobe.

Statistical analysis. All data in the text and tables are presented as mean ( \pm standard deviation). Measurements and indexes of cardiopulmonary function were compared at the same time points with a multivariate analysis of variance. The $F$ ratio of the analysis of variance was considered to be significant at $p$ values smaller than 0.05 . Differences were tested by the Scheffe $F$ test.

\section{Results}

No patients died during hospitalization. Five of the 18 patients had cardiopulmonary complications after operation. Supraventricular arrhythmias occurred in four patients, one of whom required mechanical ventilation for 3 days after operation because of respiratory failure. One patient with pneumonia and atelectasis required frequent bronchoscopies after operation. Although one of the three patients who underwent pneumonectomy had an arrhythmia, the other patients who underwent pneumonectomy had uneventful postoperative courses. Complications developed in four of the 15 patients who underwent lobectomy.

Table I displays the predicted postoperative $\mathrm{FEV}_{1.0}, \mathrm{FEV}_{1.0} \%$, predicted postoperative VC, predicted postoperative \%VC, preoperative RVEF, and effects of exercise on RVEF. Patients with a preoperative $\mathrm{FEV}_{1.0 \%}$ of less than $75 \%$ had a higher rate of complications, as did patients with a predicted postoperative $\mathrm{FEV}_{1.0}$ of less than $1.8 \mathrm{~L}$. Patients with a predicted postoperative $\mathrm{VC}$ of less than $2 \mathrm{~L}$ also had a higher rate of complications, as did patients with a predicted postoperative $\% \mathrm{VC}$ of less than $65 \%$. There were no significant differences in length of stay among patients with a preoperative $\mathrm{FEV}_{1.0 \%}$ of less than $75 \%$, a predicted postoperative $\mathrm{FEV}_{1.0}$ of less than 1.8 $\mathrm{L}$, a predicted postoperative VC of less than $2 \mathrm{~L}$, or a predicted postoperative $\% \mathrm{VC}$ of less than $65 \%$. There was no association between preoperative RVEF and postoperative complications or length of stay. Patients were also classified according to the effects of exercise on RVEF. Patients with exercise-induced decrease in RVEF had a higher rate of complications than did patients with exercise-induced increase in RVEF (50\% vs $0 \%$, respectively) and longer postoperative hospitalization (37.5 \pm 15.9 vs $19.4 \pm 8.0$ days, respectively).

Patients were grouped according to preoperative RVEF value as follows: RVEF of at least $45 \%$ (group Ia, $n=8$ ) and RVEF less than 45\% (group Ib, $n=10$ ). Hemodynamic variables are shown in Table II and pulmonary function variables are shown in Table III. The average age did not differ significantly between groups. During exercise, both groups showed significant increases in $\mathrm{HR}$, mean $\mathrm{BP}$, mean PAP, and CO, although they showed no significant differences in RVEF. The postoperative values of HR, mean BP, 
Table II. Differences in hemodynamic parameters related to RVEF and response to exercise

\begin{tabular}{|c|c|c|c|c|}
\hline & \multicolumn{2}{|c|}{ Preoperative RVEF (\%) } & \multicolumn{2}{|c|}{ Effects of exercise on RVEF } \\
\hline & $\geq 45$ & $<45$ & Increase & Decrease \\
\hline No. of patients & 8 & 10 & 8 & 10 \\
\hline Pneumonectomy/lobectomy & $1 / 7$ & $2 / 8$ & $2 / 6$ & $1 / 9$ \\
\hline Age $(y \mathrm{r})$ & $63 \pm 8$ & $62 \pm 7$ & $60 \pm 7$ & $64 \pm 7$ \\
\hline \multicolumn{5}{|l|}{ HR } \\
\hline Before operation & $69.8 \pm 7.6$ & $72.1 \pm 12.0$ & $66.6 \pm 8.8$ & $74.6 \pm 10.5$ \\
\hline Exercise & $87.8 \pm 11.7^{*}$ & $88.1 \pm 16.3^{*}$ & $80.1 \pm 14.1^{*}$ & $94.2 \pm 10.9^{*}$ \\
\hline After operation & $78.9 \pm 11.9$ & $78.0 \pm 16.6$ & $72.9 \pm 7.4$ & $82.8 \pm 17.2$ \\
\hline \multicolumn{5}{|l|}{$\mathrm{BP}$} \\
\hline Before operation & $99.0 \pm 14.8$ & $93.1 \pm 11.7$ & $99.8 \pm 12.8$ & $92.5 \pm 13.0$ \\
\hline Exercise & $109.0 \pm 14.8^{*}$ & $108.0 \pm 12.9^{*}$ & $115.0 \pm 10.4^{*}$ & $103.0 \pm 13.7^{*}$ \\
\hline After operation & $95.9 \pm 9.3$ & $90.2 \pm 12.2$ & $97.4 \pm 10.5$ & $89.0 \pm 10.5$ \\
\hline \multicolumn{5}{|l|}{ PAP } \\
\hline Before operation & $16.3 \pm 2.6$ & $15.4 \pm 3.3$ & $16.9 \pm 3.5$ & $14.9 \pm 2.1$ \\
\hline Exercise & $23.6 \pm 9.1^{*}$ & $25.2 \pm 7.0^{*}$ & $20.5 \pm 6.1$ & $27.7 \pm 7.8^{*}$ \\
\hline After operation & $15.8 \pm 2.3$ & $16.5 \pm 3.1$ & $15.4 \pm 2.0$ & $16.8 \pm 3.2$ \\
\hline \multicolumn{5}{|l|}{$\mathrm{CO}$} \\
\hline Before operation & $5.52 \pm 0.97$ & $5.16 \pm 1.24$ & $5.10 \pm 1.51$ & $5.50 \pm 0.69$ \\
\hline Exercise & $7.74 \pm 1.29^{*}$ & $7.38 \pm 2.31^{*}$ & $7.40 \pm 2.31^{*}$ & $7.65 \pm 1.30^{*}$ \\
\hline After operation & $5.79 \pm 0.60$ & $4.87 \pm 0.66$ & $5.13 \pm 0.93$ & $5.40 \pm 0.64$ \\
\hline \multicolumn{5}{|l|}{ RVEF } \\
\hline Before operation & $48.3 \pm 2.1$ & $36.8 \pm 6.2$ & $41.6 \pm 9.1$ & $42.1 \pm 6.5$ \\
\hline Exercise & $47.9 \pm 4.1$ & $36.6 \pm 7.8$ & $44.3 \pm 9.8^{*}$ & $39.5 \pm 7.1^{*}$ \\
\hline After operation & $42.5 \pm 6.3$ & $33.5 \pm 4.2$ & $38.9 \pm 9.1$ & $36.4 \pm 4.6^{*}$ \\
\hline
\end{tabular}

All values are mean $\pm \mathrm{SD}$.

${ }^{*} p<0.05$ vs before operation.

mean PAP, CO, and RVEF in both groups did not significantly differ from preoperative values. In groups $\mathrm{Ia}$ and $\mathrm{Ib}$, there were no significant differences between preoperative and measured postoperative values of $\mathrm{FEV}_{1.0} \%$, nor were there differences between the predicted postoperative and measured postoperative values of $\mathrm{FEV}_{1.0}, \mathrm{VC}$, or \% $\mathrm{VC}$.

The patients were further classified according to whether exercise produced an increase (group IIa, $n=8$ ) or a decrease (group IIb, $n=10$ ) in RVEF before operation. The data are summarized in Tables II and III. The average ages in group IIa and group IIb were $60 \pm 7$ and $64 \pm 7$ years, respectively (difference not significant). Both groups revealed a significant increase in $\mathrm{HR}$, mean $\mathrm{BP}$, and $\mathrm{CO}$ during exercise; there was a change in mean PAP in group IIb but not in group IIa. RVEF increased significantly in group IIa but decreased in group IIb. In both groups, postoperative HR, mean BP, mean $\mathrm{PAP}$, and $\mathrm{CO}$ did not differ significantly from the preoperative values; however, postoperative RVEF decreased significantly in group IIb but not group IIa. In group IIa, the postoperative $\mathrm{FEV}_{1.0} \%$ was not significantly different from the preoperative value; however, there was a significant decrease in
$\mathrm{FEV}_{1.0} \%$ in group IIb. In group IIa, the measured postoperative $\mathrm{FEV}_{1.0}, \mathrm{VC}$, and \% $\mathrm{VC}$ were significantly higher than the predicted postoperative values.

\section{Discussion}

Traditional methods of assessing the operative risk for lung resection have provided only a modest ability to predict postoperative mordibity and mortality. ${ }^{18,19}$ This study examined the postoperative courses of patients undergoing lung resections and evaluated the significance of cardiopulmonary variables as indicators of postoperative risk. Previous studies yielded conflicting results regarding the use of preoperative pulmonary function testing as a predictor of postoperative complications. Some investigators have noted that patients with a depressed $\mathrm{FEV}_{1.0}$ had a high mortality rate when undergoing surgical resection for lung cancer,${ }^{20-22}$ and a strong correlation has been identified between predicted postoperative expiratory volumes and subsequent morbidity and mortality. ${ }^{22,23}$ In contrast, others have found no significant difference in $\mathrm{FEV}_{1.0}$ between survivors and nonsurvivors among patients undergoing pneumonectomy or lobectomy. ${ }^{24,25}$ In 
Table III. Differences in lung function parameters related to RVEF and response to exercise

\begin{tabular}{|c|c|c|c|c|}
\hline & \multicolumn{2}{|c|}{ Preoperative RVEF } & \multicolumn{2}{|c|}{ Effects of exercise on RVEF } \\
\hline & $\geq 45$ & $<45$ & Increase & Decrease \\
\hline No. of patients & 8 & 10 & 8 & 10 \\
\hline \multicolumn{5}{|l|}{$\mathrm{FEV}_{1.0}(\mathrm{~L})$} \\
\hline Before operation & $2.30 \pm 0.63$ & $2.25 \pm 0.55$ & $2.47 \pm 0.48$ & $2.12 \pm 0.61$ \\
\hline Predicted & $1.71 \pm 0.42$ & $1.67 \pm 0.45$ & $1.87 \pm 0.34$ & $1.55 \pm 0.44$ \\
\hline After operation & $1.74 \pm 0.51$ & $1.79 \pm 0.69$ & $2.20 \pm 0.43^{*}$ & $1.42 \pm 0.4$ \\
\hline \multicolumn{5}{|l|}{$\mathrm{FEV}_{1.0} \%$} \\
\hline Before operation & $78.0 \pm 10.3$ & $77.4 \pm 4.9$ & $81.8 \pm 5.7$ & $74.3 \pm 7.2$ \\
\hline After operation & $74.9 \pm 12.1$ & $75.1 \pm 9.58$ & $84.1 \pm 5.24$ & $67.7 \pm 7.22 \uparrow$ \\
\hline \multicolumn{5}{|l|}{$\mathrm{VC}(\mathrm{L})$} \\
\hline Before operation & $2.98 \pm 0.84$ & $2.95 \pm 0.71$ & $3.05 \pm 0.70$ & $2.89 \pm 0.81$ \\
\hline Predicted & $2.21 \pm 0.57$ & $2.15 \pm 0.62$ & $2.29 \pm 0.53$ & $2.08 \pm 0.63$ \\
\hline After operation & $2.33 \pm 0.59$ & $2.33 \pm 0.73$ & $2.64 \pm 0.57^{*}$ & $2.08 \pm 0.62$ \\
\hline \multicolumn{5}{|l|}{$\% \mathrm{VC}$} \\
\hline Before operation & $92.9 \pm 14.7$ & $91.9 \pm 19.5$ & $88.6 \pm 16.0$ & $95.4 \pm 18.1$ \\
\hline Predicted & $68.7 \pm 11.9$ & $67.0 \pm 11.7$ & $68.9 \pm 11.4$ & $66.9 \pm 12.1$ \\
\hline After operation & $69.9 \pm 12.2$ & $70.0 \pm 12.7$ & $74.2 \pm 11.1^{*}$ & $66.6 \pm 12.3$ \\
\hline
\end{tabular}

All values are mean \pm standard deviation. No statistical analyses between preoperative and postoperative values for $\mathrm{FEV}$,.. $\mathrm{VC}$, or \% VC because pulmonary resection usually produces significant decreases. $F E V_{1.0} \%, \mathrm{FEV}_{1.0} / \mathrm{FVC}$.

* $p<0.05$ vs predicted.

$t p<0.05$ vs before operation.

our study, $\mathrm{FEV}_{1.0}$ was not in any case a significant predictor of postoperative events. We also found that a low preoperative $\mathrm{FEV}_{1.0}$ predicted a low postoperative $\mathrm{FEV}_{1.0}$, a low postoperative $\mathrm{VC}$, and a low postoperative \%VC but did not correlate with the frequency of postoperative complications or with postoperative length of stay. These results suggest that lung resection may be well tolerated even in patients with ventilatory impairment. In our study, four of the 15 patients who underwent lobectomy had complications (27\%) and one of the three patients who underwent pneumonectomy had an arrhythmia $(33 \%)$. The main reason for the relatively high complication rate among patients who underwent lobectomy was the thorough dissection of the mediastinal lymph nodes.

We previously suggested that the main cause of right ventricular dysfunction after major pulmonary resection is related to changes in right ventricular afterload. ${ }^{9}$ An increase in pulmonary vascular resistance leads to strain on the right side of the heart, contributing to the relatively high frequency of cardiovascular complications documented in previous reports. ${ }^{26,27}$ We therefore assessed right ventricular function as a predictor of postoperative complications in this study. We found that a low preoperative RVEF did not correlate with postoperative morbidity. Because many physicians have questioned this type of risk assessment, others have investigated the value of preoperative exercise testing. ${ }^{7,28,29}$ These tests have not met with widespread use because they are expensive and labor-intensive, and few data are available to assess their accuracy. Oxygen requirements differ for patients at rest versus exercising patients; however, a clear relationship between resting variables and exercise tolerance in patients awaiting lung resection has not been established. For these reasons, there is increasing interest in the role of exercise testing in the evaluation of cardiopulmonary impairment. Furthermore, exercise testing may identify cardiovascular disease that was previously undiagnosed in these patients.

Our study was designed to examine the contribution of right ventricular function to exercise capacity, and more specifically to determine the utility of evaluating RVEF during exercise as a predictor of postoperative complications. Although a few studies have examined the relationship between RVEF and pulmonary resection, ${ }^{30,31}$ measurements were not obtained during exercise as well as at rest. In our study, a decreased RVEF with exercise was a significant marker of patients at high risk for the development of complications. RVEF has been reported to remain unchanged in normal subjects during exercise. ${ }^{32}$ Decrease in RVEF with exercise may be a result of underlying emphysematous changes of the lungs and of tumor-induced atelectasis. It also may reflect latent cardiopulmonary disease. 
Although there is little correlation between postoperative course and magnitude of impairment demonstrated by spirometric variables or right ventricular performance at rest, a stronger correlation has been found between postoperative course and right ventricular performance during exercise. This apparent discrepancy relates to the fact that exercise capacity is an interactive process that depends on pulmonary function, cardiac status, and peripheral oxygen use. Partial failure of one of these three functions will affect the others, yet borderline impairment can be compensated for by adequate function of the other variables. It is possible that patients with marginal pulmonary function are able to maintain an adequate cardiopulmonary status after lung resection because of compensatory cardiac mechanisms and improved peripheral oxygen use. With exercise, respiratory distress can develop when right ventricular contractility reaches its limitation in increasing pulmonary blood flow. After a lung resection, the pulmonary vascular bed is reduced and may no longer be adequate to accommodate an increased oxygen demand. We found that patients with a preoperative RVEF of less than $45 \%$ had no significant deterioration in hemodynamics or pulmonary function after operation. Patients with decreased RVEF on exercise before operation had a significant decline in RVEF after pulmonary resection. On the other hand, patients who had an increased RVEF with exercise had no significant change in hemodynamics after operation. The difference between measured postoperative values and predicted postoperative values reflects latent postoperative pulmonary functional reserve. In those patients who had an increased RVEF with exercise, the measured postoperative $\mathrm{FEV}_{1.0}, \mathrm{VC}$, and \% VC were significantly higher than the predicted postoperative values, suggesting that exercise-induced change in RVEF could be an indicator of functional reserve.

The performance of the right ventricle, particularly during exercise, may be a limiting factor after reduction of the vascular bed associated with pulmonary resection. Deterioration of RVEF during exercise appears to be related to the effects of cardiopulmonary functional reserve. Because this study included only a small number of patients, however, additional investigations may be necessary to define the utility of RVEF in the preoperative evaluation of patients who are undergoing lung resection for cancer. In addition, further studies are warranted to determine whether right ventricular function can be evaluated by less invasive methods, such as echocardiography, that can easily be applied in routine clinical practice.

\section{REFERENCES}

1. Olsen GN, Block AJ, Swenson EW, Castle JR, Wynne JW. Pulmonary function evaluation of the lung resection candidate: a prospective study. Am Rev Respir Dis 1975;111:37987.

2. Miller JI, Grossman GD, Hatcher CR. Pulmonary function test criteria for operability and pulmonary resection. Surg Gynecol Obstet 1981;153:893-5.

3. Gass GD, Olsen GN. Preoperative pulmonary function testing to predict postoperative morbidity and mortality. Chest 1986;89:127-35.

4. Ferguson MK, Little L, Rizzo L, Popovich KJ, Glonek GF, Cek A, et al. Diffusing capacity predicting morbidity and mortality after lung resection. J Thorac Cardiovasc Surg 1988;96:894-900

5. Markos J, Mullen BP, Hillman DR, Musk AW, Antico VF, Lovegrove FT, et al. Preoperative assessment as a predictor of mortality and morbidity after lung resection. Am Rev Respir Dis 1989;139:902-10.

6. Smith TP, Kinasewitz GT, Tucker WY, Spillers WP, George RB. Exercise capacity as a predictor of post-thoracotomy morbidity. Am Rev Respir Dis 1984;129:730-3.

7. Epstein SK, Faling LJ, Daly BD, Celli BR. Predicting complications after pulmonary resection: pre-operative exercise testing versus a multifactorial cardiopulmonary risk index. Chest 1993;104:694-700.

8. Colman NC, Schraufnagel DE, Rivington RN, Pardy RL. Exercise testing in evaluation of patients for lung resection. Am Rev Respir Dis 1982;125:604-6.

9. Okada M, Ota T, Okada M, Matsuda H, Okada K, Ishii I. Right ventricular dysfunction after major pulmonary resection. J Thorac Cardiovasc Surg 1994;108:503-11.

10. Hoffman MJ, Greenfield LJ, Sugarman HJ, Tatum JL. Unsuspected right ventricular dysfunction in shock and sepsis. Ann Surg 1983;197:307-17.

11. Klinger JR, Hill NS. Right ventricular dysfunction in chronic obstructive pulmonary disease: evaluation and management. Chest 1991;99:715-23.

12. Spinale FG, Mukherjee R, Tanaka R, Zile MR. The effects of valvular regurgitation on thermodilution ejection fraction measurements. Chest 1992;101:723-31.

13. Mukherjee R, Spinale FG, von Recum AF, Crawford FA. In vitro validation of a right ventricular thermodilution ejection fraction system. Ann Biomed Eng 1991;19:165-77.

14. Kay HR, Afshari M, Barash P, Webler W, Iskandrian A, Bemis C, et al. Measurement of ejection fraction by thermal dilution techniques. J Surg Res 1983;34:337-46.

15. Dubois AB, Botelho SY, Bedell GN, Marshall R, Comroe JH Jr. A rapid plethysmographic method for measuring thoracic gas volume: a comparison with a nitrogen washout method for measuring functional residual capacity in normal subjects. J Clin Invest 1956;35:322-6.

16. Goldman HI, Becklake MR. Respiratory function tests: normal values at median altitudes and the prediction of normal results. Am Rev Respir Dis 1959;79:457-75.

17. Wernly JA, DeMeester TR, Kirchner PT, Myerowitz PD, Oxford DE, Golomb HM. Clinical value of quantitative 
ventilation-perfusion lung scans in the surgical management of bronchogenic carcinoma. J Thorac Cardiovasc Surg 1980; 80:535-43.

18. Keagy BA, Lores ME, Starek PJ, Murray GF, Lucas CL, Wilcox BR. Elective pulmonary lobectomy: factors associated with morbidity and operative mortality. Ann Thorac Surg 1985;40:349-52.

19. Kohman LJ, Meyer JA, Ikins PM; Oates RP. Random versus predictable risks of mortality after thoracotomy for lung cancer. J Thorac Cardiovasc Surg 1986;91:551-4.

20. Boushy SF, Billing DM, North LB, Helgason AH. Clinical course related to preoperative and postoperative pulmonary function in patients with bronchogenic carcinomà. Chest 1971;59:383-91.

21. Mittman C. Assessment of operative risk in thoracic surgery. Am Rev Respir Dis 1961;84:197-207.

22. Wahi R, McMurtrey MJ, DeCaro LF, Mountain CF, Ali MK, Smith TL. Determinants of perioperative morbidity and mortality after pneumonectomy. Ann Thorac Surg 1989;48:33-7.

23. Kearney DJ, Lee TH, Reilly JJ, DeCamp MM, Sugarbaker DJ. Assessment of operative risk in patients undergoing lung resection. Chest 1994;105:753-9.

24. Didolkar MS, Moore RH, Takita H. Evaluation of the risk in pulmonary resection for bronchogenic carcinoma. Am J Surg 1974;127:700-3.

25. Keagy BA, Schorlemmer GR, Murray GF, Starek PJ, Wilcox
BR. Correlation of preoperative pulmonary function testing with clinical course in patients after pneumonectomy. Ann Thorac Surg 1983;36:253-7.

26. Patel RL, Townsend ER, Fountain SW. Elective pneumonectomy: factors associated with morbidity and operative mortality. Ann Thorac Surg 1992;54:84-8.

27. Busch E, Verazin G, Antkowiak JG, Driscoll D, Takita H. Pulmonary complications in patients undergoing thoracotomy for lung carcinoma. Chest 1994;105:760-6.

28. Olsen GN, Weiman DS, Bolton JW, Gass GD, McLàin WC, Schoonover GA, et al. Submaximal invasive exercise testing and quantitative lung scanning in the evaluation for tolerance of lung resection. Chest 1989;95:267-73.

29. Bechard D, Wetstein L. Assessment of exercise oxygen consumption as preoperative criterion for lung resection. Ann Thorac Surg 1987;44:344-9.

30. Lewis JW, Bastanfar M, Gabriel F, Mascha E. Right heart function and prediction of respiratory morbidity in patients undergoing pneumonectomy with moderately severe cardiopulmonary dysfunction. J Thorac Cardiovasc Surg 1994; 108:169-75.

31. Reed CE, Spinale FG, Crawford FA. Effect of pulmonary resection on right ventricular function. Ann Thorac Surg 1992;53:578-82.

32. Heywood JT, Grimm J, Hess OM, Jakob M, Krayenbuhl HP. Right ventricular diastolic function during exercise: effect of ischemia. J Am Coll Cardiol 1990;16:611-22. 